\title{
Mental Health Crisis 911 Calls, Resources, and Inequality
}

\author{
Emma Frankham, University of Wisconsin-Madison \\ orcid.org/0000-0001-7040-5941
}

Is socioeconomic status a predictor of mental health-related 911 calls independent of mental health? Answering this question is important because knowing which factors are associated with mental health-related calls could influence effective resource allocation. I analyze census tractlevel data across three cities and find that a lack of financial resources is positively associated with mental health-related calls, independent of poor mental health. I argue that individuals of low socioeconomic status rely on this public safety net more so than affluent individuals, and that this is an under-recognized mechanism by which individuals of low socioeconomic status with mental illness come into contact with police.

Keywords: mental illness; police; socioeconomic status 


\section{Introduction}

Despite decades of research indicating that the socioeconomic status of persons with mental illness in jails and prisons is low, little is known about the mechanisms by which these individuals come into contact with police in the first place. This is an important omission because police are often among the first responders in mental health crises and police have been described as "streetcorner psychiatrists" (Teplin and Pruett 1992).

Since the 1970 s it has been established that individuals with mental illness are overrepresented among those who experience arrest (Steadman, Vanderwyst, and Ribner 1978). In more recent research, a meta-analysis of twenty-two qualitative and quantitative studies estimated that $25 \%$ of individuals with mental illness and $40 \%$ of individuals with serious mental illness have been arrested at some point in their lifetime (Livingston 2016).

Furthermore, those with mental illness who are arrested are likely to be of low socioeconomic status. For example, research has indicated that those with serious mental illness who have been arrested at some point in their lifetime are more likely than individuals with serious mental illness who have not been arrested at some point in their lifetime to: have obtained a lower level of education and have experienced unemployment or homelessness in the past six months (White et al. 2006). In a study examining the characteristics of patients with serious mental illness admitted to hospitals in the Greater Baltimore area, it was found that patients of low socioeconomic status were more likely than patients of medium or high socioeconomic status to have been arrested at some point in their lifetime (Muntaner et al. 1998).

Therefore, it has been established that: A) Individuals with serious mental illness who have experienced arrest are more likely than individuals with serious mental illness who have not experienced arrest to have a lower level of education and have experienced unemployment or 
homelessness (White et al. 2006). And B) Individuals with serious mental illness who are of low socioeconomic status are more likely to have experienced arrest during their lifetime than individuals with serious mental illness of higher socioeconomic status (Muntaner et al. 1998; White et al. 2006).

However, we know little about the mechanisms by which individuals with mental illness of lower socioeconomic status come into contact with police in the first place. I propose that one such mechanism is mental health-related 911 calls. These calls are particularly time-consuming and resource-intensive (Charette, Crocker, and Billette 2014). Furthermore, although they only account for approximately $1 \%$ of all 911 calls (Livingston 2016), 25\% of police fatal shootings involve persons in mental health crisis (Fuller et al. 2015). Of these, approximately $81 \%$ were initiated by a 911 call and the most common cause of police contact for those with mental illness killed by police was a 911 call made by a family member or friend (41\%) (Frankham 2018). Therefore, these 911 calls may result in arrest and further criminal justice system contact, or even injury or death.

There is a burgeoning research area that examines how effective specialized mental health crisis training is for police officers who respond to these calls, as well as the effectiveness of jaildiversion programs to minimize arrest rates for those experiencing a mental health crisis that results in police intervention. For example, there is a plethora of research on the effectiveness of the Crisis Intervention Team model for improving the safety of police interactions (for police, the public, and the individual experiencing a mental health crisis) and successfully diverting individuals away from arrest and toward emergency psychiatric referral (Compton et al. 2014; Compton et al. 2008; Watson 2010). This model of training, established by the National Alliance of Mental Illness, is considered to be the "gold standard" in law enforcement mental health 
training and educates police officers on topics including: medications and side effects; alcohol and drug assessment; suicide prevention; personality disorders; co-occurring disorders; posttraumatic stress disorders; and crisis de-escalation training (DuPont, Cochran, and Pillsbury 2007).

However, there is little research that focuses on the demand-side of these calls. In particular, are mental health-related 911 calls most likely to originate from areas of lower socioeconomic status? Furthermore, is socioeconomic status a better predictor of the rate of mental health-related calls in a census tract than estimates of mental health itself? Answering these questions is important because knowing which factors at a census tract-level are associated with high rates of mental health-related calls could be used to better predict which geographic areas may benefit from more mental health resource allocation. For example, training police officers in mental illness crisis training in particular areas, increasing mental illness preventative healthcare in particular areas, and police departments partnering with social workers in particular areas to accompany police officers on mental health-related calls. This is similar to how many police departments use hot spots policing to identify areas of concentrated crime and respond to these areas by focusing resources on these areas (Braga, Papachristos, and Hureau 2014).

This paper examines the use of resources (calling 911 in a mental health-related crisis) across space (within three cities) by census tract to test the hypothesis that access to resources and inequality (as indicated by low socioeconomic status) is associated with emergency services resource use in a mental health crisis. This paper argues that the stratifying process of needing to call 911 in a mental health-related crisis is a mechanism for police contact that perpetuates class and socioeconomic status inequalities in the criminal justice system, from initial police contact to potential arrest. 


\section{$\underline{\text { Literature Review }}$}

This literature review explores several research areas. First, the factors that influence the likelihood of an individual experiencing a mental health crisis. Following this, the factors that influence a 911 call being made in a situation where an individual is experiencing a mental health crisis. Third, to provide some context about the potential outcomes of these 911 calls, I will discuss research on mental health-related call dispositions with a particular focus on likelihood of arrest.

\section{Factors that Influence the Likelihood of Experiencing a Mental Health Crisis}

The likelihood of an individual experiencing mental illness, and a potential mental health crisis that could result in a mental health-related 911 call, in their lifetime is influenced by an array of factors that are encompassed by the biopsychosocial model (Engel 1977). This model takes into account not only biological factors, such as genetics and neurochemistry, but also psychological factors, such as personality type and behavior, and social factors such as sociocultural context, social support, and socioeconomic status (Engel 1977). Broadly, a mental health crisis encompasses a situation where there is a need for immediate action or intervention (Frankham 2019). For example, if an individual has disappeared, is likely to harm themselves or others, or is threatening, talking about, or making specific plans for suicide (Frankham 2019).

Low socioeconomic status has been long-established as being associated with mental illness (Dohrenwend and Dohrenwend 1969; Dohrenwend et al. 1980; Kessler et al. 1994; Kessler et al. 2005). In 2017, unemployed adults in the United States were over twice as likely to have serious mental illness compared to adults with full-time employment ( $7.5 \%$ of adults versus $3.7 \%$ of adults) (Substance Abuse and Mental Health Services Administration 2018b). College graduates are less likely than those who have not graduated from college to have serious mental 
illness, and those at less than $100 \%$ of the federal poverty level in 2017 were more than twice as likely as those at $200 \%$ or more of the federal poverty level to have serious mental illness $(7.3 \%$ of adults versus 3.6\% of adults) (Substance Abuse and Mental Health Services Administration 2018b).

From a sociological perspective, researchers have emphasized the importance of social integration in protecting mental well-being (Durkheim 1897/1951; Thoits and Hewitt 2001). In addition, poverty and inequality is associated with poor mental health (Link and Phelan 1995; McLeod 2013) and low socioeconomic status and lack of social support have been described as “fundamental causes" of health inequalities (Link and Phelan 1995: 80). Socioeconomic status is associated with access to resources, such as knowledge and social connections, that can be used to either avoid risk or minimize the consequences of disease (Link and Phelan 1995), in this context mental illness. Social support in particular may be regarded as a buffer against stressful life events that may contribute toward mental illness. For example, research has indicated a positive relationship between income and perceived social support, with acute negative life events and traumas potentially mediating and inhibiting the ability of individuals of lower socioeconomic status to mobilize social support (Mickelson and Kubzansky 2003). Researchers have also noted that disparities between socioeconomic status and disease and death are more pronounced for preventable causes of disease and death (Phelan et al. 2004). Experiencing a mental health crisis could be regarded as preventable, given that early diagnosis and treatment could help prevent severe mental illness deterioration.

We have also known since early ecological studies that individuals with mental illness are overrepresented in neighborhoods that are of low socioeconomic status (Faris and Dunham 1960; Srole 1962; Dear and Wolch 1987; Wolch and Dear 1993). Such neighborhoods typically have 
high rates of unemployment and crime (Wilson 1987), and low levels of informal social control mechanisms, such as collective efficacy, which can help protect against unfavorable social conditions (Sampson, Raudenbush, and Earls 1997). More recent research indicates similar findings with regard to mental illness and social cohesion (Echeverria et al. 2008), socioeconomic status (Galea et al. 2007), and crime (Weisburd et al. 2018). Lastly, exposure to community violence, anti-social behaviour, discrimination, and stress is associated with higher rates of mental illness (Egan et al. 2008).

Exposure to high levels of police surveillance may itself have consequences for mental health, and research conducted in New York City has indicated that invasive police encounters in particular can increase anxiety symptoms (Geller et al. 2014) and that men in particular experience heightened levels of nervousness in these neighborhoods (Sewell, Jefferson, and Lee 2016). Therefore, it is difficult to ascertain whether poor mental health is exogenous to policing or caused by policing.

Debate continues over whether the association between low socioeconomic status and mental illness is causative or a product of social selection. If the relationship is causative, one would expect low socioeconomic status to precede mental illness. If, on the other hand, the association between mental illness and low socioeconomic status is a product of social selection, one would expect to see individuals sorted into socioeconomic status by mental health, with mental illness preceding low socioeconomic status. Some research has indicated that both mechanisms likely contribute to the association between low socioeconomic status and mental illness and that it is difficult to untangle causal direction (Anderson 2018; Dohrenwend et al. 1992). 


\section{Factors that Influence the Likelihood of a Mental Health-Related 911 Call Being Made}

If, and when, individuals experience mental health crises, not all of these will be observed in the form of a 911 call. Of the many mental health crises experienced in each of the three cities examined in this paper, many are unobserved. Only a portion (and it is difficult to estimate how many) will be observed in the sense that they will be recorded by 911 calls. Many individuals will experience a mental health crisis alone, or alternative routes of action will be taken other than an individual calling 911, such as a family member or friend helping them or taking them to the emergency room for psychiatric referral without police intervention.

It should be made clear that if, and why, a mental health-related call is made to police is likely motivated by reasons different from those for reporting violent crime. Whether individuals call police to report violent crime has been well-researched, both quantitatively and qualitatively. In particular, researchers have underscored the importance of legal cynicism, the belief that the criminal justice system is incompetent and unresponsive, in understanding why low socioeconomic, communities of color are reluctant to engage with police (Baumer 2002; Carr, Napolitano, and Keating 2007; Kirk and Papachristos 2011). Instead, within these communities a code of conduct may emerge where residents sanction each other informally without the need for police intervention (Anderson 1999; Kirk and Papachristos 2011; Sampson 2012). However, other researchers have found mixed results with regard to the attitudes of youth living in highcrime neighborhoods - while youth may be negatively disposed toward police, youth also tend to favor increased law enforcement (Carr, Napolitano, and Keating 2007).

The mental health-related calls that we observe likely do involve individuals of low socioeconomic status. This is because individuals with serious mental illness are particularly at risk for needing to use safety net services, such as public hospitals, emergency services, and 
other state and federal programs (Lewin and Altman 2000) and these services are the primary sources of care for low-income individuals (Chow, Jaffee, and Snowden 2003). Furthermore, in contrast to theories regarding why individuals of low socioeconomic status may not report violent crime, informal sanctions and the "code of the streets" (Anderson 1999) are arguably not applicable to mental health crises. This is because while a mental health crisis is not mutually exclusive with violence, informal sanctions are likely to be ineffective and inapplicable to those in crisis. Furthermore, even if police contact is made, it is more likely to be initiated by either family members or the individual who is experiencing the crisis themselves calling 911 than it is a member of public (Charette, Crocker, and Billette 2011; Frankham 2018; Watson and Wood 2017). Therefore, because of how contact is initiated and the inapplicability of legal cynicism to these calls, it is likely than the sociodemographic factors associated with not engaging in police for the reporting of violent crime are different for those when engaging with the police to report a mental health crisis that requires urgent psychiatric treatment.

Research has examined associations between socioeconomic status and indicators of collective efficacy at the census tract-level and rates of emergency mental health-related 911 calls. For example, a study of the count of mental health-related 911 calls in San Francisco that occurred between 2001 and 2003 found that the percentage of renters in a given census tract is positively associated with a higher count of mental health-related 911 calls (Kessell et al. 2009). Specifically, a one percentage point increase in the percentage of renters by census tract was associated with a $1 \%$ increase in the rate of mental health-related calls (Kessell et al. 2009). This finding remained after controlling for race/ethnicity, sex, percentage of persons living below the poverty level, and median age. High levels of renters in a census tract are likely to be correlated with low income and high residential turnover, both of which are associated with resources, 
neighborhood stability, and collective efficacy. However, other studies of mental health-related police interactions (including both calls for service and police-initiated interactions) have found mixed results with regard to associations between the percentage of renters in a census tract and the rate of mental health-related police interactions (Vaughan et al. 2018).

Research in this area is limited and to date studies have failed to examine associations of estimates of mental health by census tract and the rate of mental health-related 911 calls. Without such information it is difficult to ascertain whether the rate of mental health-related 911 calls is merely a reflection of the distribution of poor mental health in the population, or whether financial resources and social connections are important predictors of the rate of mental healthrelated calls independent of poor mental health. Furthermore, while the associations between some sociodemographic characteristics of census tracts and counts of mental health-related calls has been examined (Kessell et al. 2009) this study failed to control for health insurance status and percent veteran in addition to not controlling for estimates of mental health. This paper not only improves upon this study by including population as an exposure variable to account for the relative risk of census tracts having higher rates of mental health-related calls, but by examining three cities instead of one (San Francisco) any relationships between socioeconomic status and rates of mental health-related calls can be regarded as more generalizable.

\section{Mental Health-Related Call Dispositions}

When a mental health crisis is observed in the form of a 911 call and police are dispatched there are four main outcomes that could occur. One is that the individual is arrested. One of the earliest robust studies in this area is an analysis of approximately 1,400 police-public interactions in Chicago which found that for similar offenses, individuals with mental illness experience a 
significantly greater probability of arrest compared to individuals without mental illness (Teplin 1984). However, more recent research has indicated that individuals with mental illness are not criminalized by police, whereby arrest is used inappropriately to resolve an encounter, and that police are not more likely to arrest individuals with mental illness compared to those without mental illness (Engel and Silver 2001). While the reasons why individuals with mental illness may or may not be arrested at a higher rate compared to those without mental illness is outside the scope of this paper, analyses indicate that within the context of 911 calls specifically, approximately 5-7\% of mental health-related calls in large cities in the United States result in arrest (Steadman et al. 2000; Teller et al. 2006; Watson and Wood 2017). ${ }^{1}$

The second outcome is that police may transport the individual to psychiatric emergency treatment, typically at a hospital. This occurs in approximately $45 \%$ of mental health-related calls to police departments with crisis intervention team training (Steadman et al. 2000; Watson and Wood 2017). This figure is likely to be lower if police have not been trained to recognize signs of mental illness and de-escalate situations involving persons with mental illness, through crisis intervention team training. It should be noted that while Seattle Police Department had a

${ }^{1}$ Steadman et al. (2000): analysis of the disposition of a sample of 300 mental health-related calls that occurred between October 1996 and August 1997 in three cities (100 from each). The three cities were Birmingham (AL), Memphis (TN), and Knoxville (TN). Teller et al. (2006): analysis of 10,004 mental health-related calls received by Akron (OH) Police Department from May 1998 through April 2004. Watson and Wood (2017): 300 Chicago Police Department police officers described to researchers what happened on 428 mental health-related calls that were responded to from July 2013 through September 2016. It should be noted that it is likely that different places experience different call dispositions because of local factors including differences in police training. 
Crisis Intervention Team during this period of analysis, Baltimore and Detroit did not (National Alliance on Mental Illness n.d.). In high poverty areas, the police play a particular crucial role in referring African-Americans, more so than Whites, to psychiatric treatment (Chow, Jaffee, and Snowden 2003).

Individuals may also be referred to psychiatric treatment by police, but not directly transported. Research has indicated that this happens in approximately $8 \%$ (Watson and Wood 2017) to $13 \%$ (Steadman et al. 2000) of mental health-related calls. Lastly, police officers may take no formal action at all, and instead they may resolve the situation informally. This occurs in just over a third of cases (Steadman et al. 2000; Teller et al. 2006; Watson and Wood 2017).

\section{Hypothesis}

The aim of this paper is to test for a relationship between indicators of socioeconomic status and the rate of mental health-related 911 calls by census tract in three cities. As discussed in the literature review above, we know that there is a positive association between low socioeconomic status, low levels of collective efficacy, and mental illness. But is there an association at the geographic-level between low socioeconomic status and mental health-related calls independent of, or controlling for, estimates of mental health in the population? In other words, if we control for the geographic distribution of poor mental health within the population, is there a relationship between low socioeconomic status and the rate of mental health-related calls? If there is, rates of mental health-related calls are not simply a reflection of the distribution of poor mental health in the population. I test the following hypothesis, which is motivated by theories of collective efficacy and associations between socioeconomic status and health, and the existing literature reviewed above. 
Hypothesis: Low socioeconomic status at the census tract level will be positively associated with both the rate of mental health-related 911 calls.

\section{Methods}

\section{Data}

The data for my analyses are from a variety of sources. For the dependent variable, publicly available data on all 911 calls occurring in Baltimore, Detroit, and Seattle during 2016 are used. This data was found using a list of publicly available 911 call data compiled by the Police Data Initiative and calls for service data are generally maintained by law enforcement computer-aided dispatch systems. These three cities were chosen because they are examples of different types of large cities across the United States. In particular, Baltimore and Detroit are examples of gutted industrial cities with high poverty rates, while Seattle is an example of a thriving post-industrial city with a progressive climate for healthcare, specifically mental health services.

The 911 dispatchers in each city assigned a code to each call based on the caller's description of the emergency. Calls were only included in my analyses if they were made by individuals in the community; calls from automated alarm systems or calls from police officers to the dispatch center were excluded. Unknown issues and unfounded calls were also excluded, as were calls made by accident. I coded call descriptions as being related to a mental health emergency when they included references to a petition for emergency psychiatric evaluation, suicide, psychiatric involuntary detention, and other mental health issues (see Appendix I for the exact text of all codes that I categorized as being related to a mental health emergency for each city). I coded mental health-related calls as " 1 " and non-mental health-related calls as " 0. " 
The original calls for service data for each of the three cities included latitude and longitude coordinates that corresponded to where each call originated from. I used Geographic information systems software (ArcGIS10) to map census tract boundaries onto the latitude and longitude coordinates that corresponded to calls for each of the three cities. Following this, I merged United States census data from the 2011-2015 American Community Survey 5-year estimates for 2015 with the 911 call data for each city by census tract. Therefore, census tracts in the data are characterized by not only the amount and type of 911 calls (mental health-related or not mental health-related) received during 2016, but also by sociodemographic information that is likely to be associated with different types of 911 calls. This information is: total population; median household income in thousands; percent of the population without health insurance; percent military veteran; median age; percent male; percent White; percent Black or African-American; percent Asian; percent Hispanic; percent other race, which includes Native American and selfidentified "other" racial or ethnic groups; and percent of the population aged 25 and over who have not graduated high school. With the exceptions of percent of the population without health insurance and percent military veteran, variables similar to those listed above are often used as independent variables in research that examines geographic-level predictors of rates of mental health-related police interactions and calls (Kessell et al. 2009; Vaughan et al. 2018).

I have included percent military veteran in the analyses because research has indicated that rates of major depressive disorder, post-traumatic stress disorder, bipolar disorder, and generalized anxiety disorder among military personnel is higher than rates of these disorders in the civilian population (Kessler et al. 2014). Furthermore, suicide rates among soldiers on active duty reached a 28 -year high in 2008 , surpassing the suicide rate among demographically similar civilians (Kuehn 2009). Therefore, it might be expected that areas with a high percentage of 
veterans may experience a higher rate of mental health-related calls. Percent of the population without health insurance is included because those without health insurance may be less likely to receive treatment for mental illness, which may increase the risk of mental illness worsening to the point of reaching a crisis stage that requires immediate intervention.

In addition to census data being used to characterize census tracts, data from the Centers for Disease Control and Prevention's 500 cities project (which provides census tract-level estimates of health for 500 large cities in the United States) is used. In particular, an estimate of respondents aged 18 years and over who report that for 14 or more days during the past 30 days their mental health was "not good" is merged with the 911 call data and census data. This mental health measure was created using the Centers for Disease Control and Prevention's Behavioral Risk Factor Surveillance System for 2015 and is based on estimates generated from self-reported mental health gathered through telephone interviews (Centers for Disease Control and Prevention 2018).

Excluded from my analyses are census tracts where the population count of people residing any of the following contribute to at least one third of the total population: jails or prisons, psychiatric institutions, or college halls of residences. Also excluded are census tracts where psychiatric institutions are located. These exclusions have been made because the rate of calls in these locations will likely be less to do with the sociodemographic characteristics of these areas, and more to do with the placement of particular institutions. Census tracts that cover the core of a downtown area have also been excluded because the high numbers of calls that are generated from these areas are less likely associated with the characteristics of the population that resides there, and more likely associated with the volume of activity in those areas. Following these exclusions, the analyses include 193 census tracts for Baltimore (5 excluded), 
286 for Detroit (6 excluded), and 127 for Seattle (6 excluded). Included in the data are 2,973 mental health-related calls from Baltimore out of 297,458 total calls (1.0\%). For Detroit, 6,665 mental health-related calls were classified out of 231,414 total calls (2.9\%). Lastly, 4,427 calls were classified as mental health-related in Seattle, out of 192,170 total calls (2.3\%). Therefore, overall for the three cities combined, 14,065 out of 721,042 calls were classified as being mental health-related (1.95\%). The population of each city is as follows: Baltimore $(596,520)$, Detroit $(679,989)$, and Seattle $(627,227)$. Figure 3.0 presents the distribution of total calls per person by call category for each city. Baltimore's rate of 911 calls per capita for non-mental health reasons is $49 \%$ higher than Detroit's and 65\% higher than Seattle's, while its rate of mental health calls per capita is half the Detroit rate and $71 \%$ of the Seattle rate. 


\section{Figure 3.0.911 Calls Per Capita, by City and Type}

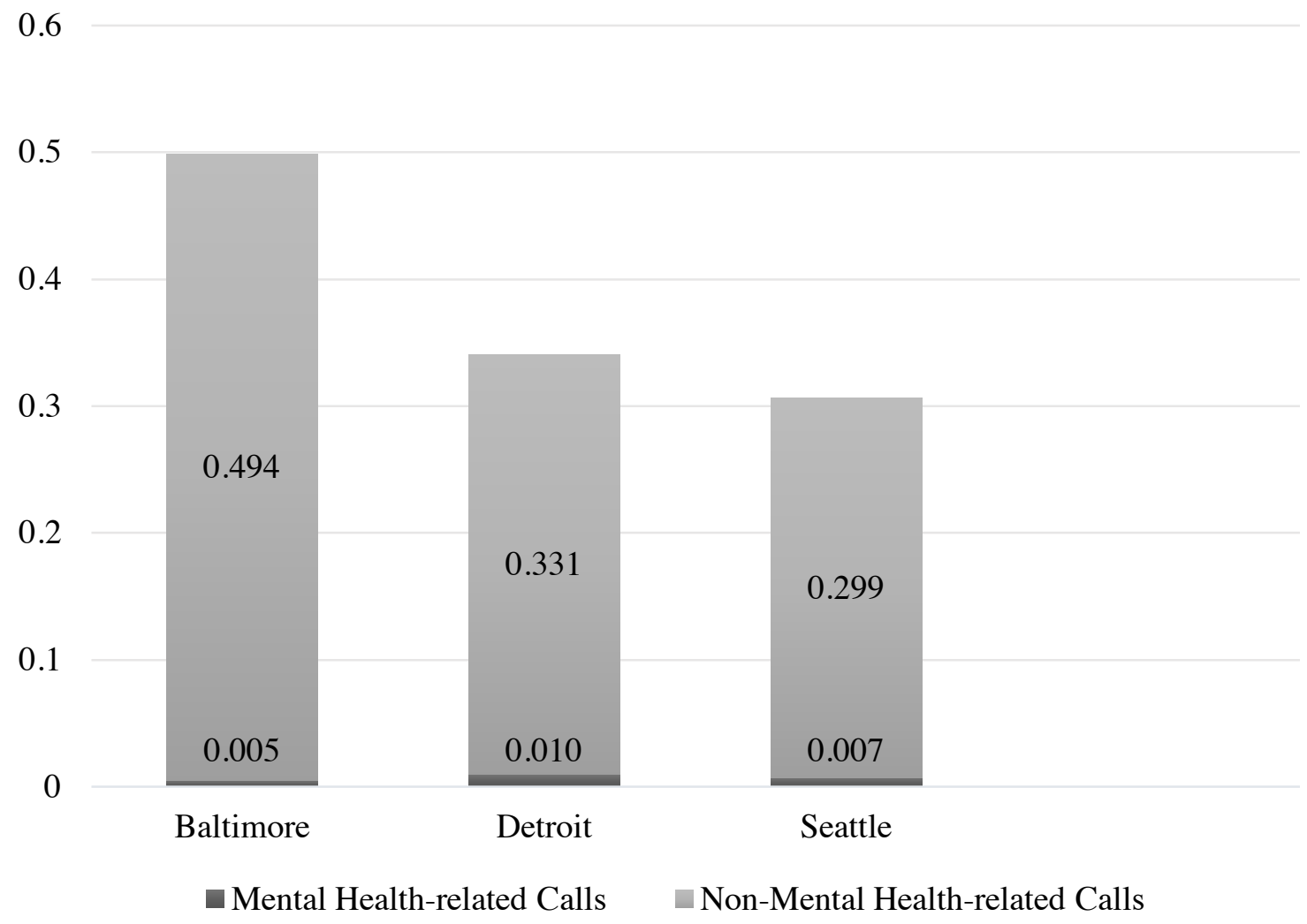

Descriptive statistics for each city by census tract are provided in Table 1.0. Some differences and similarities between the three cities are notable. First, the mean count of mental health-related calls by census tract is higher in Seattle than Baltimore or Detroit. Second, Seattle residents are on average less likely than residents in Baltimore or Detroit to have not graduated high school or to be Black. Third, residents in Seattle are on average more likely than residents in Baltimore or Detroit to be Asian, and earn more. Table 1.0 also provides information on Pearson chi-squared significance levels comparing the means of each descriptive statistic by city. Descriptive statistics for the combined three-city sample by census tract are provided in Table 1.1.

(Tables 1.0-1.1 here) 


\section{Analytic Approach}

Data from each city has been combined into one dataset to increase both the sample size and the statistical power of the analyses. The 911 call data are overdispersed because there are few or no mental health-related 911 calls in many census tracts and the variance of the count measure exceeds the mean. Therefore, I use negative binomial regression to estimate associations between the rate of mental health-related 911 calls by census tract and the independent variables in all three cities. Negative binomial regression is suitable when the data are overdispersed because it relaxes assumptions that the variance is equal to the mean and that counts of the dependent variable are statistically independent (King 1989). Results are estimated when population in hundreds is logged and included as an offset to account for the at-risk population. This restores the rate distribution of the data and the logged population coefficient is a constant with a fixed value of one so this coefficient is not reported (see Disha, Cavendish, and King 2011; Osgood 2000).

The following focal independent variables are included: median income in thousands; percent of the population without health insurance; percent of renter-occupied housing units; and percent of the population aged 25 and over who have not graduated high school. The following independent variables are used as controls: mental health as estimated by the Center for Disease Control and Prevention; percent military veteran; median age; percent male; percent White; percent Black or African-American; percent Asian; percent Hispanic; percent other race; and non-mental health-related calls in hundreds. Because data from all three cities are combined, I control for city to account for any variation between cities that may be due to unobserved city heterogeneity. 


\section{$\underline{\text { Results }}$}

First, I explore relationships between the variables of interest using correlation and these results are displayed in Table 1.2. Several correlations are of note. First, percent without health insurance (.265), percent Black (.195), and percent with poor mental health (.255) are all positively correlated with percent of mental health-related calls by census tract. Median income is negatively correlated with percent of mental health-related calls by census tract (-.277). Percent reporting poor mental health is strongly positively correlated with percent Black (.672), percent who have not graduated high school (.784), and percent without health insurance (.628). Furthermore, poor mental health is particularly strongly negatively correlated with income (-.844). Variables that are positively associated with the count of non-mental health-related calls include percent Asian (.199), percent male (.141), and percent renter (.294). Variables that are negatively associated with the count of non-mental health-related calls include percent Black ($.129)$, poor mental health (-.102), and percent without health insurance (-.103). Therefore, the variables that correlate with mental health-related calls do not correlate in the same way (if at all) with non-mental health-related calls. Overall, these correlations suggest that there is not only a relationship between mental health related-calls, socioeconomic status, and mental health, but that there is also a relationship between poor mental health itself and socioeconomic status. These relationships are explored further in negative binomial regression analyses below.

(Table 1.2 here)

Table 1.3 displays results from Model 1 which estimates factors associated with the rate of mental health-related calls. The exponentiated regression coefficients from this model estimation are reported as incidence rate ratios, which can be interpreted as a measure of relative risk. The 
slope equals the predicted factor change in mental health-related 911 calls for a one-unit change in the predictor. This model therefore asks the question: "In which census tracts are individuals most vulnerable to coming into contact with police by means of a mental health-related call?"

Looking at Table 1.3, several control variables are associated with the outcome variable. Both the Detroit and Seattle city indicators are statistically significant $(p<.001)$ with very high incident rate ratios (Detroit: 2.119; Seattle: 1.889), so that the rate of mental health calls is over twice as high in Detroit as Baltimore, and 89\% higher in Seattle than Baltimore, indicating that compared to Baltimore these cities experience a higher rate of mental health-related 911 calls. It is difficult to ascertain whether this result is reflective of the "true" rate of mental health-related calls being lower in Baltimore compared to Detroit or Seattle, or whether this is reflective of a high rate of mental health-related calls being falsely categorized as not mental health-related in Baltimore. It is unlikely that non-mental health-related calls would be falsely categorized as mental health-related, but the reverse is true. This is because calls that are categorized as being mental health-related are likely to be the most moderate to severe cases if they are identifiable by information given by the caller alone. Implications of this are explored further in the conclusion.

Another important control variable for the rate of mental health-related calls is the count of non-mental health-related calls. For each increase of 100 in the count of non-mental healthrelated calls, mental health-related calls are predicted to increase by $3.1 \%(p<.001) .{ }^{2}$ It is

\footnotetext{
${ }^{2}$ Correlations between types of 911 calls by city are explored in Appendix II in Tables 1.5-1.7. Of note is that in all three cities there is a strong correlation between the number of non-mental health-related calls per capita and the number of mental health-related calls per capita. The correlations are most similar for Baltimore (.684) and Detroit (.654), while Seattle has a particularly high correlation (.936). Therefore, in Seattle there may be a stronger relationship between counts of non-mental health-related calls and counts of mental health-related calls when compared to Baltimore or Detroit.
} 
known that individuals with mental illness are overrepresented in neighborhoods that typically have high rates of crime (Weisburd et al. 2018; Wilson 1987) and low levels of informal social control mechanisms, such as collective efficacy which can help protect against unfavorable social conditions (Sampson et al. 1997). Therefore, this positive association between non-mental health-related 911 calls and mental health-related calls is perhaps to be expected.

Median age is positively associated with the rate of mental health-related calls, although the magnitude of the association is small. Results indicate that a one-year increase in median age is associated with a $1.1 \%$ increase in the rate of mental health-related calls. This finding is consistent with other research which finds that median age is positively associated with mental health-related calls (Kessell et al. 2009). Potential explanations for the former include research findings that often younger individuals view police less favorably than older individuals (Brown and Benedict 2002). If this is the case, perhaps older individuals are more likely than younger individuals to call the police about either themselves or loved ones experiencing a mental health crisis. Another potential explanation is that the prevalence of mental illness, and therefore potential mental health crises, increases with age. However, first onset of mental illness has usually occurred by young adulthood (Kessler et al. 2007) and self-report estimates indicate that the prevalence of serious psychological distress does not increase with age (National Center for Health Statistics 2018). Therefore, it is more likely that the positive association between age and rate of mental health-related calls is due to changes in police trust by age or changes in social support than it is due to an increase in the prevalence of mental illness.

The percentage of males in a census tract is also positively associated with the rate of mental health-related calls. The results indicate that a one percentage point increase in the percentage of males in a census tract is associated with an increase in the rate of mental health- 
related calls by $1.1 \%(p<.05)$. This finding is also consistent with other research, although others report that the magnitude of the association is higher (one percentage point increase in the percentage of males in a census tract is associated with an increased in the count of mental health-related calls by 6\%) (Kessell et al. 2009). Other research poses some potential explanations as to why this may be, despite the fact that men are less likely than women to experience serious psychological distress (National Center for Health Statistics 2018). In particular, research has indicated that there are higher levels of help-seeking behavior among women (Addis and Mahalik 2003), women tend to have larger social networks which increases opportunities for the exchange of health information with supportive persons (Umberson and Karas Montez 2010), and men with mental illness are more likely than women with mental illness to commit a violent offense (Crocker, Hartford, and Heslop 2009). For these reasons, it is a reasonable finding that the percentage of men in a census tract is positively associated with rates of mental health-related calls.

Both the percentage of Asians and Hispanics by census tract is negatively associated with the rate of mental health-related calls. Regarding the former, a one percentage point increase in the percentage of Asians by census tract is associated with a $0.9 \%$ decrease in the rate of mental health-related calls $(p<.05)$, while a one percentage point increase in the percentage of Hispanics by census tract is associated with a $0.8 \%$ decrease in the rate of mental health-related calls $(p<.05)$.

The relationships between race/ethnicity, immigration, language, and mental health-related calls is difficult to disentangle. For example, African-Americans, Asians, and Hispanics may experience "double stigma" when stigma experienced by individuals as a racial/ethnic minority overlaps with stigma experienced by individuals who have mental illness (Gary 2005). This 
double stigma experienced by racial/ethnic minorities may result in prejudice and discrimination, decreased well-being, increased mortality (Gary 2005), or the delay or forgoing of treatment altogether (Alvidrez, Snowden and Kaiser 2008; Gary 2005). Research has also indicated that compared to Whites or English-speaking Hispanics, Spanish speakers are less likely to enter treatment through emergency services (Folsom et al. 2007) and Asians are also more likely to access the mental health treatment at a higher level of illness severity compared to Whites (Kung 2003). Therefore, it could be expected that racial/ethnic minorities included in this analysis would be associated with higher rates of mental health-related calls because of the delaying of treatment.

However, other research has indicated that, at least among Spanish-speaking Hispanics, strong family ties and social support may act as a buffer against negative effects of mental illness (Lopez et al. 2004; Vega et al. 1999). Furthermore, Asians born in the United States have an estimated lower prevalence of mental illness compared to African-Americans or Hispanics born in the United States (Williams, Costa, and Leavell 2017). Therefore, this research points toward it being likely that the percentage of Hispanics and Asians by census tract would be associated with lower rates of mental health-related calls. Perhaps the findings with regard to the negative association between percentage Hispanic and Asian and mental health-related calls are more supportive of research that highlights differences in prevalence of mental illness and social support networks by race/ethnicity.

Of the focal independent variables, both median income and percent renter are statistically significant. Regarding the former, each $\$ 1000$ increase in median income is associated with a $0.8 \%$ decrease in the rate of mental health-related calls, a negative association between income and the rate of mental health-related calls. This could be because in higher median income areas 
individuals are less likely to have mental illness in the first place because of the availability of resources for these individuals that may be used to either avoid risk of mental illness or minimize the effects of it (Link and Phelan 1995). Additionally, individuals in higher median income areas may not need to either call 911 themselves or have another individual call 911 in a mental health crisis. This is because individuals of high socioeconomic status do not rely on safety net emergency services in the absence of other treatment options as much as individuals of low socioeconomic status (Chow, Jaffee, and Snowden 2003; Lewin and Altman 2000).

Percent renter is positively associated with mental health-related calls. While the positive association is small, this finding is consistent with other research which finds that a one percentage point increase in the percentage of renters in a census tract is associated with a $1 \%$ increase in the count of mental health-related calls (Kessell et al. 2009). Reasons for this include that high levels of renters in a census tract are likely to be correlated with high residential turnover, which is associated with resources, neighborhood stability, and collective efficacy.

There is no association between the other focal independent variables (percent of the population aged 25 and over who have not graduated high school and percent of population with no insurance) and mental health-related calls. Therefore, of the socioeconomic factors that may predict rates of mental health-related calls, median income and percent renters are more powerful predictors of rates of mental health-related calls by census tract. The null finding for the association between education level, percent without health insurance, and rates of mental health-related calls may be accounted for when we consider that both education level and health insurance status may be indicative of earnings potential, and thus potential predictive power is accounted for by median income.

Therefore, several factors are important when we consider the following question: "In 
which census tracts are individuals most vulnerable to coming into contact with police by means of a mental health-related call?" Specifically, median age, percent male, count of non-mental health-related calls, and percent renter are all positively associated with the rate of mental healthrelated calls by census tract. Household median income, percent Asian, and percent Hispanic are negatively associated with the rate of mental health-related calls by census tract. Surprisingly, given the correlation between poor mental health and percent of mental health-related calls displayed in Table $1.2(.255)$ estimates of poor mental health are not statistically significant in Model 1 . This may in part be due to the particularly high correlation between median income and poor mental health (-.844) and this is explored further in analyses below.

(Table 1.3 here)

Table 1.4 displays the results from the estimation of three additional negative binomial regression models that specifically explore the relationship between poor mental health, income, and rates of mental health-related 911 calls. The results from Model 2 indicate that when both median income and poor mental health are included as independent variables along with the basic controls, only median income is statistically significant and each $\$ 1000$ increase is associated with a $1.4 \%$ decrease in the rate of mental health-related calls $(p<.001)$. However, the results of Model 3 indicate that there is a strong relationship between poor mental health and the rate of mental health-related calls once median income is not included as an independent variable. The results from Model 3 indicate that for every percentage point increase in the percent of individuals who report poor mental health, the rate of mental health-related calls by census tract increases by $7.6 \%(p<.001)$. When only median income is included in the model (Model 4) the association between median income and the rate of mental health-related calls is 
stronger than when both median income and poor mental health are included as independent variables.

Overall, the results of these model estimations indicate that because of the high correlation between median income and poor mental health, when both are included in Model 2 poor mental health is no longer statistically significant because median income is a stronger predictor. Therefore, median income is an important predictor of the rate of mental health-related calls by census tract, more so than estimates of poor mental health itself. ${ }^{3}$

(Table 1.4 here)

\section{Discussion and Conclusion}

This paper tested the hypothesis that low socioeconomic status in the three cities studied (as indicated by percent renters, low education level, and percent without health insurance) will be positively associated with the rate of mental health-related 911 calls. Furthermore, that higher socioeconomic status in the three cities studied (as indicated by median income) will be negatively associated with the rate of mental health-related 911 calls. To test this hypothesis I used 911 call data, census data, and health data from the Centers for Disease Control and Prevention. Results indicate support for the hypothesis in the negative binomial regression estimations.

These results are consistent with research that highlights low socioeconomic status and lack of social support as "fundamental causes" of health inequalities (Link and Phelan 1995: 80),

\footnotetext{
${ }^{3}$ These model estimations are replicated by city and the results are displayed in Tables $1.8-1.10$ in Appendix III. The results by city are remarkably similar to the results when census tracts from all cities are included in the same model estimations (displayed in Table 1.4).
} 
in this instance manifested through higher rates of mental health-related 911 calls for census tracts that are particularly low income. While research has indicated that emergency services are the primary sources of care for low-income individuals (Chow, Jaffee, and Snowden 2003), research to date has not established an association between low income in the aggregate and rates of emergency mental health services through 911 calls. As for why low income matters, the results suggest that low rates of collective efficacy, low rates of social support, and exposure to community violence (all of which are associated with poor mental health - see Echeverria et al. 2008; Egan et al. 2008; Link and Phelan 1995; and Mickelson and Kubzansky 2003) may be mechanisms.

Other research has indicated that individuals with serious mental illness who are of low socioeconomic status are more likely to experience arrest during their lifetime than individuals with serious mental illness of higher socioeconomic status (Muntaner et al. 1998; White et al. 2006). The findings from this paper point toward these calls being a mechanism by which individuals of low socioeconomic status with mental illness come into contact with police. From this initial point of contact, arrest may then occur. Specifically, research indicates that approximately 5-7\% of mental health-related calls in large cities in the United States result in arrest (Steadman et al. 2000; Teller et al. 2006; Watson and Wood 2017). Situating this figure in the context of the data used in this paper, this means that up to 1,000 of the 14,065 mental healthrelated calls examined may have resulted in arrest.

Research that indicates that those who have experienced arrest are more likely than those who have had no criminal justice system contact to avoid "surveilling institutions" that keep formal records, such as medical facilities (Brayne 2014). Therefore, individuals who experience mental health crises and who are therefore particular at need for medical services, may in fact 
further avoid treatment as a result of criminal justice system contact. This is particularly problematic given that this paper has indicated that this population is likely to be of low socioeconomic status with few resources to begin with.

This study's limitations include the meaningfulness of census tracts as a geographic boundary versus other geographic units, such as neighborhoods, how mental health-related calls are recorded across the three cities studied, and the self-report measure of poor mental health. Regarding the geographic unit of analysis, it may be that differences between neighborhoods are more sociodemographically meaningful than differences between census tracts. In particular, there may be subtler factors present at the neighborhood-level that influence the rate of mental health-related 911 calls, such as neighborhood-level resources, social disorganization, and collective efficacy, that are not captured by information that is available at the census tract-level. For these reasons I have chosen not to discuss census tracts as being akin to neighborhoods, instead I argue that census tracts in a more minimalistic sense than neighborhoods, aggregates of attributes of individuals. However, if neighborhoods were used as the geographic unit of analysis instead of census tracts, associations between income and mental health-related 911 calls would likely become even greater. This is because differences across neighborhoods would be likely be more acute given their larger geographic size and smaller quantity compared to census tracts.

Regarding how mental health-related calls are classified, three issues need to be considered. First, successful recording of mental health-related calls by 911 call operators may vary by city. For example, it is not likely that the count of mental health-related 911 calls truly is lower in Baltimore (1.0\%) than Detroit $(2.9 \%)$ or Seattle $(2.3 \%)$. Rather, it is possible that 911 call operators in Baltimore are not recording mental health-related calls as such. Reasons may include differences in call operator training and differences in software use. 
Second, across all cities it is likely that many mental health-related calls do not get classified as such and therefore the false-negative rate of call classification is high. This is because only moderate to severe mental health-related calls may be easily identifiable by information given by the caller alone. Therefore, the dependent variable, mental health-related calls, may only capture moderate to severe cases pertaining to mental illness. An implication of this is that the statistically significant predictor variables may only be predictive of particular types of mental health-related calls.

Furthermore, there may be sociodemographic differences in how calls are classified as being mental health-related. For example, sociodemographic differences in how individuals speak about mental illness or have awareness of mental illness may affect how 911 call operators classify calls. It is difficult to say how this may affect the interpretation of the results except to caution, again, that there may be a selection effect occurring for the types of calls that are classified as being mental health-related.

A third limitation of this analysis is the value of the Centers for Disease Control and Prevention census tract-level estimates of respondents aged 18 years and over who report 14 or more days during the past 30 days during which their mental health was "not good." This measure was chosen because it captures a broad range of mental health issues, rather than specifically asking about depression for example, and because it is a self-report measure it does not depend on mental illness diagnosis (which is itself influenced by sociodemographic factors and willingness to seek treatment). On the other hand, this means that the disadvantages of this measure include that it likely correlates with stress, and that perceptions of mental health being "not good" are subjective and may be influenced by sociodemographic factors. 


\section{Future Directions for Research}

The merging of not only 911 call data but also census data and data on health from the Centers for Disease Control and Prevention across three major cities has created a precedent for how these types of data may be used together to answer other important research questions. First, does the key finding that socioeconomic status is associated with the rate of mental health-related calls remain in medium or small cities, or even rural areas? There may be geographic-level factors, such as degree of inequality or racial/ethnic segregation, that may be more variable in larger cities versus smaller cities or rural areas. These factors may in turn influence the extent to which socioeconomic status is associated with the rate of mental health-related 911 calls in different areas. Social networks may also form and operate differently in rural areas, potentially minimizing the need for police intervention in a mental health crisis. Furthermore, police officers in smaller police departments may have closer relationships with individuals and caregivers who rely on these safety net services more so than police officers in larger police departments. However, it would be difficult to capture these factors quantitatively at the census tract-level and a qualitative approach may be more appropriate.

Second, are there any other indicators of socioeconomic status that are important? Future research should explore other indicators of socioeconomic status. For example, this paper has not included employment status or percent of individuals below 100 percent of the federal poverty level. There may also be other control variables that are important that have not been considered here. For example, marital status, average household or family size, or disability status.

Third, future research should consider why health insurance status does not appear to be associated with the rate of mental health-related calls. This is surprising because percent without health insurance may be viewed as a proxy for access to preventative healthcare that may either 
alleviate or prevent a mental health crisis from occurring. However, access to healthcare does not necessarily mean that the healthcare provided is good quality (and therefore individuals show a willingness to use it) or that even if this healthcare is "good," that it is effective at preventing a mental health crisis. It may be that one is true and not the other, or that both negate the usefulness of considering health insurance status in the context of relying upon safety net services such as calling 911 in a mental health crisis.

Lastly, and arguably most importantly, how can police departments effectively react to knowledge that low socioeconomic status is predictive of higher rates of mental health-related calls? In geographic areas that have the characteristics of places where the rate of mental healthrelated calls may be particularly high, police departments could respond by concentrating mental health resources in these areas. For example, if a police department does not have the resources to train all officers in Crisis Intervention Team training, perhaps at least officers in areas that are at risk for a high rate of mental health-related calls could be trained. There is general consensus about the effectiveness of this type of training for improving the safety of police interactions for all involved and successfully diverting individuals away from arrest and toward emergency psychiatric referral (Compton et al. 2014; Compton et al. 2008; Watson 2010). Therefore, similar to how many police departments use hot spots policing to identify areas of concentrated crime and respond by focusing resources on these areas (Braga, Papachristos, and Hureau 2014), an approach could be used where "hot spots" of mental health crises be identified, either through examining 911 call data or by acknowledging the geographic-level factors that are associated with a high rate of mental health-related calls.

There have also been concerns raised by mental health advocacy organizations over the use of calling 911 in a mental health crisis in the first place. For example, if possible mental 
health crises could be responded to by medical personal or personnel with specialized mental health training (Mental Health America n.d.). Alternatively, a co-responder model could be utilized whereby both police and personnel with mental health training are dispatched together to mental health crisis calls where the individual with particular mental health expertise leads the assessment, rather than police leading the assessment and making decisions about psychiatric referral (Mental Health America n.d.). Knowledge of where the areas are that are likely to experience high rates of mental health-related calls could be used to inform where the strategic placement of co-responding teams and mental health personnel could be best utilized. 


\section{Bibliography}

Addis, Michael E. and James R. Mahalik. 2003. "Men, Masculinity, and the Contexts of Help Seeking." American Psychologist 58(1):5-14.

Alvidrez Jennifer, Lonnie R. Snowden, and Dawn M. Kaiser. 2008. "The Experience of Stigma among Black Mental Health Consumers." Journal of Health Care for the Poor and Underserved 19:874-893.

Anderson, Elijah. 1999. Code of the Street: Decency, Violence, and the Moral Life of the Inner City. New York C, NY: Norton.

Anderson, Lewis Robert. 2018. "Adolescent Mental Health and Behavioural Problems, and Intergenerational Social Mobility: A Decomposition of Health Selection Effects." Social Science \& Medicine 197:153-160.

Baumer, Eric. 2002. "Neighborhood Disadvantage and Police Notification by Victims of Violence." Criminology 40(3):579-616.

Braga, Anthony A., Andrew V. Papachristos, and David M. Hureau. 2014. "The Effects of Hot Spots Policing on Crime: An Updated Systematic Review and Meta-analysis." Justice Quarterly 31(4): 633-663.

Brayne, Sarah. 2014. "Surveillance and System Avoidance: Criminal Justice Contact and Institutional Attachment." American Sociological Review 79(3):367-391.

Bronson, Jennifer and Marcus Berzofsky. 2017. Bureau of Justice Statistics Special Report NCJ 250612. Indicators of Mental Health Problems Reported by Prisoners and Jail Inmates, 2011-12.

Brown, Ben and Wm R. Benedict. 2002. "Perceptions of the Police: Past Findings, lindent Methodological Issues, Conceptual Issues and Policy Implications.” Policing: An International Journal of Police Strategies \& Management 25(3):543-580.

Carr, Patrick J., Laura Napolitano, and Jessica Keating. 2007. "We Never Call the Cops and Here is Why: A Qualitative Examination of Legal Cynicism in Three Philadelphia Neighborhoods." Criminology 45(2):445-480.

Centers for Disease Control and Prevention. 2018. "Methodology." Retrieved February 12, 2019 (https://www.cdc.gov/500cities/methodology.htm).

Charette, Yanick, Anne G. Crocker, and Isabelle Billette. 2011. "The Judicious Judicial Dispositions Juggle: Characteristics of Police Interventions Involving People with a Mental Illness." Canadian Journal of Psychiatry 56(11):677-685.

Charette, Yanick, Anne G. Crocker, and Isabelle Billette. 2014. "Police Encounters Involving Citizens with Mental Illness: Use of Resources and Outcomes." Psychiatric Services 65(4):511-516.

Chow, Julian, Kim Jaffee, and Lonnie Snowden. 2003. "Racial/Ethnic Disparities in the Use of Mental Health Services in Poverty Areas." American Journal of Public Health 93(5):792 $-797$.

Compton, Michael T., Masuma Bahora, Amy C. Watson, and Janet R. Oliva. 2008. “A Comprehensive Review of Extant Research on Crisis Intervention Team (CIT) Programs." Journal of the American Academy of Psychiatry \& the Law 36:47-55.

Compton, Michael T., Roger Bakeman, Beth Broussard, Dana Hankerson-Dyson, Letheshia Husbands, Shaily Krishan, Tarianna Stewart-Hutto, Barbara M. D’Orio, Janet R. Oliva, Nancy J. Thompson, and Amy C. Watson. 2014. "The Police-based Crisis Intervention 
Team (CIT) Model: II. Effects on Level of Force and Resolution, Referral, and Arrest." Psychiatric Services 65(4):523-529.

Crocker, Anne G., Kathleen Hartford, and Lisa Heslop. 2009. "Gender Differences in Police Encounters Among Persons With and Without Serious Mental Illness." Psychiatric Services 60(1):86-93.

Dear, Michael and Jennifer Wolch. 1987. Landscapes of Despair: From Deinstitutionalization to Homelessness. Princeton, NJ: Princeton University Press.

Disha, Ilir, James C. Cavendish, and Ryan D. King. 2011. "Historical Events and Spaces of Hate: Hate Crimes against Arabs and Muslims in Post-9/11 America." Social Problems 58(1):21-46.

Dohrenwend, Bruce P. and Barbara S. Dohrenwend. 1969. Social Status and Psychological Disorder. New York, NY: Wiley.

Dohrenwend, Bruce P., Barabara S. Dohrenwend, Madelyn Gould, Bruce Link, Richard Neugebauer, and Robin Wunsch-Hitzig. 1980. Mental Illness in the United States: Epidemiological Estimates. New York, NY: Praeger.

Dohrenwend, Bruce P., Itzhak Levav, Patrick Shrout, Sharon Schwartz, Guedalia Naveh, Bruce Link, Andrew Skodal, and Ann Stueve. 1992. "Socioeconomic Status and Psychiatric Disorders: The Causation Selection Issue.” Science 255 (5047):946-952.

DuPont, Randolph, Sam Cochran, and Sarah Pillsbury. 2007. Crisis Intervention Team Core Elements. Retrieved February 10, 2019 (http://www.cit.memphis.edu/information_files/CoreElements.pdf).

Durkheim, Emile. 1897/1951. Suicide: A Study in Sociology. New York, NY: Free Press. Echeverria, Sandra, Ana V. Diez-Roux, Steven Shea, Luisa N. Borrell, and Sharon Jackson. 2008. "Associations of Neighborhood Problems and Neighborhood Social Cohesion with Mental Health and Health Behaviors: The Multi-ethnic Study of Atherosclerosis." Health \& Place 14(4):853-865.

Egan, Matt, Carol Tannahill, Mark Petticrew, and Sian Thomas. 2008. "Psychosocial Risk Factors in Home and Community Settings and Their Associations with Population Health and Health Inequalities: A Systematic Meta-review." BMC Public Health 8(1):239-251.

Engel, G. 1977. "The Need for a New Medical Model: A Challenge for Biomedicine." Science 196(4286):129-136.

Engel, Robin S. and Eric Silver. 2001. "Policing Mentally Disordered Suspects: A Reexamination of the Criminalization Hypothesis." Criminology 39:225-252.

Faris, Robert E. L. and Warren H. Dunham. 1960. Mental Disorders in Urban Areas: An Ecological Study of Schizophrenia and Other Psychoses. New York, NY: Hafner Publishing Co.

Folsom, David P., Todd Gilmer, Concepcion Barrio, David J. Moore, Jesus Bucardo, Laurie A. Lindamer, Piedad Garcia, William Hawthorne, Richard Hough, Thomas Patterson, Dilip V. Jeste. 2007. "A Longitudinal Study of the Use of Mental Health Services by Persons with Serious Mental Illness: Do Spanish-speaking Latinos Differ from English-speaking Latinos and Caucasians?" The American Journal of Psychiatry 164:1173-1180.

Frankham, Emma. 2018. "Mental Illness Affects Police Shootings." Contexts 17(2):70-72.

Frankham, Emma. 2019. "When to Call 911 in an Urgent Mental Health Situation." Scholars Strategy Network. Retrieved April 13, 2019 (https://scholars.org/contribution/when-call -911-urgent-mental-health-situation). 
Fuller, Doris A., H. Richard Lamb, Michael Biasotti, and John Snook. 2015. Overlooked in the Undercounted: The Role of Mental Illness in Fatal Law Enforcement Encounters. Retrieved November 12, 2016 (http://www.treatment advocacycenter.org/storage/documents/overlooked-in-the-undercounted.pdf).

Galea, Sandro, Jennifer Ahern, Arijit Nandi, Melissa Tracy, John Beard, and David Vlahov. 2007. "Urban Neighborhood Poverty and the Incidence of Depression in a Population -based Cohort Study." Annals of Epidemiology 17(3):171-179.

Gary, Faye A. 2005. “Stigma: Barrier to Mental Health Care Among Ethnic Minorities.” Issues In Mental Health Nursing 26(10):979-999.

Geller, Amanda, Jeffrey Fagan, Tom Tyler, and Bruce G. Link. 2014. "Aggressive Policing and the Mental Health of Young Urban Men." The American Journal of Public Health 104(12):2321-2327.

James, Doris J. and Lauren E. Glaze. 2006. Bureau of Justice Statistics Special Report: Mental Health Problems of Prison and Jail Inmates. NCJ 213600.

Kessell, Eric R., Jennifer Alvidrez, William A. McConnell, and Martha Shumway. 2009. "Effect of Racial and Ethnic Composition of Neighborhoods in San Francisco on Rates of Mental Health-Related 911 Calls." Psychiatric Services 60(10):1376-1378.

Kessler, Ronald C., G. Paul Amminger, Sergio Aguilar-Gaxiola, Jordi Alonso, Sing Lee, and T. Bedirhan Üstün. 2007. "Age of Onset of Mental Disorders: A Review of Recent Literature." Current Opinion in Psychiatry 20(4):359-364.

Kessler, Ronald C., Wai T. Chiu, Olga Demler, and Ellen E. Walters. 2005. "Prevalence, Severity, and Comorbidity of 12-Month DSM-IV Disorders in the National Comorbidity Survey Replication." Archives of General Psychiatry 62(6):617-627.

Kessler, Ronald C., Steven G. Heeringa, Murray B. Stein, Lisa J. Colpe, Carol S. Fullerton, Irving Hwang, James A. Naifeh, Matthew K. Nock, Maria Petukhova, Nancy A. Sampson, Michael Schoenbaum, Alan M. Zaslavsky, Robert J. Ursano, and Army STARRS collaborators. 2014. "Thirty-day Prevalence of DSM-IV Mental Disorders among Nondeployed Soldiers in the US Army." JAMA Psychiatry 71(5):504-513.

Kessler, Ronald C., Katherine A. McGonagle, Shenyang Zhao, Christopher B. Nelson, Michael Hughes, Suzann Eshleman, Hans-Ulrich Wittchen, and Kenneth S. Kendler. 1994. Lifetime and 12-Month Prevalence of DSM-III-R Psychiatric Disorders in the United States: Results from the National Comorbidity Survey." Archives of General Psychiatry 51(1):8-19.

King, Gary. 1989. "Event Count Models for International Relations: Generalizations and Applications. ” International Studies Quarterly 33(2):123-198.

Kirk, David and Andrew Papachristos. 2011. "Cultural Mechanisms and the Persistence of Neighborhood Violence.” American Journal of Sociology 116(4):1190-1233.

Kuehn, Bridget M. 2009. "Soldier Suicide Rates Continue to Rise: Military, Scientists Work to Stem the Tide." JAMA 301(11):1111-1113.

Kung, Winnie W. 2003. “Chinese Americans' Help Seeking for Emotional Distress.” Social Service Review 77(1):110-134.

Lewin, Marion E. and Stuart H. Altman. 2000. America's Health Care Safety Net: Intact but Endangered. Washington, D.C.: Institute of Medicine. 
Link, Bruce G. and Jo Phelan. 1995. "Social Conditions as Fundamental Causes of Disease." Journal of Health and Social Behavior (extra issue):80-94.

Livingston, James D. 2016. "Contact Between Police and People with Mental Disorders: A Review of Rates.” Psychiatric Services 67(8): 850-857.

López, Steven Regeser, Kathleen H. Nelson, Antonio J. Polo, Janis H. Jenkins, Marvin Karno, Christi Vaughn, and Karen S. Snyder. 2004. "Ethnicity, Expressed Emotion, Attributions, and Course of Schizophrenia: Family Warmth Matters." Journal of Abnormal Psychology 113(3):428-439.

McLeod, Jane D. 2013. "Stratification and Inequality." Pp. 229-253 in Handbook of the Sociology of Mental Health ( $2^{\text {nd }}$ edition), edited by C. S. Aneschensel, J. C. Phelan, and A. Bierman. New York, NY: Springer.

Mental Health America. N.d. "Position Statement 59: Responding to Behavioral Health Crises." Retrieved April 16, 2019 (http://www.mentalhealthamerica.net/issues/position-statement -59-responding-behavioral-health-crises).

Mickelson, Kristin D. and Laura D. Kubzansky. 2003. "Social Distribution of Social Support: The Mediating Role of Life Events.” American Journal of Community Psychology 32(3/4):265-281.

Muntaner, Carles, Paula Wolyniec, John Mcgrath, and Ann Pulver. 1998. "Arrest Among Psychotic Inpatients: Assessing the Relationship to Diagnosis, Gender, Number of Admissions, and Social Class." Social Psychiatry and Psychiatric Epidemiology 33(6):274-82.

National Alliance on Mental Illness. N.d. "Crisis Intervention (CIT) Programs.” Retrieved April 23, 2019 (https://www.nami.org/get-involved/law-enforcement-and-mental-health).

National Center for Health Statistics. 2018. "Figure 13.2. Percentage of Adults Aged 18 and Over who Experienced Serious Psychological Distress During the Past 30 Days, by Age Group and Sex: United States, January-June 2018." National Health Interview Survey, Sample Adult Core Component. Retrieved February 8, 2019 (https://public.tableau.com/profile/nhis\#!/vizhome/FIGURE13_2/Dashboard13_2).

Osgood, D. Wayne. 2000. "Poisson-Based Regression Analysis of Aggregate Crime Rates." Journal of Quantitative Criminology 16(1):21-43 (Special Issue: Longitudinal Analysis).

Phelan, Jo C., Bruce G. Link, Ana Diez-Roux, Ichiro Kawachi, and Bruce Levin. 2004. "'Fundamental Causes' of Social Inequalities in Mortality: A Test of the Theory." Journal of Health and Social Behavior 45(3):265-285.

Sampson, Robert. 2012. Great American City: Chicago and the Enduring Neighborhood Effect. Chicago, IL: University of Chicago Press.

Sampson, Robert, Stephen W. Raudenbush, and Felton Earls. 1997. "Neighborhoods and Violent Crime: A Multilevel Study of Collective Efficacy." Science 277:918-924.

Sewell, Abigail A., Kevin A. Jefferson, and Hedwig Lee. "Living Under Surveillance: Gender, Psychological Distress, and Stop-Question-and-Frisk Policing in New York City." Social Science \& Medicine 159:1-13.

Snowden Lonnie R. and Jane Holschuh. 1992. "Ethnic Differences in Emergency Psychiatric Care and Hospitalization in a Program for the Severely Mentally Ill." Community Mental Health Journal 28:281-290. 
Srole, Leo. 1962. Mental Health in the Metropolis: The Midtown Manhattan Study: Thomas A.C.Rennie Series in Social Psychiatry. New York, NY: Blakiston Division, McGraw -Hill.

Steadman, Henry J., Donna Vanderwyst, D., and Stephen Ribner. 1978. "Comparing Arrest Rates of Mental Patients and Criminal Offenders." The American Journal of Psychiatry 135(10):1218-1220.

Steadman, Henry J., Martha Williams Deane, Randy Borum, and Joseph P. Morrissey. 2000. "Comparing Outcomes of Major Models of Police Responses to Mental Health Emergencies." Psychiatric Services 51(5):645-49.

Substance Abuse and Mental Health Services Administration. 2018a. Key Substance Use and Mental Health Indicators in the United States: Results from the 2017 National Survey on Drug Use and Health. (HHS Publication No. SMA 18-5068, NSDUH Series H-53).

Substance Abuse and Mental Health Services Administration. 2018b. "Results from the 2017 National Survey on Drug Use and Health: Detailed Tables.” Retrieved November 14, 2018 (https://www.samhsa.gov/data/report/2017-nsduh-detailed-tables).

Teller, Jennifer L. S., Mark R. Munetz, Karen M. Gil, and Christian Ritter. 2006. "Crisis Intervention Team Training for Police Officers Responding to Mental Disturbance Calls." Psychiatric Services 57(2):232-237.

Teplin, Linda A. 1984. "Criminalizing Mental Disorder: The Comparative Arrest Rate of the Mentally Ill." American Psychologist 39(7):794-803.

Teplin, Linda A. and Nancy S. Pruett. 1992. "Police as Streetcorner Psychiatrist: Managing the Mentally Ill.” International Journal of Law and Psychiatry 15:139-156.

Thoits, Peggy A. and Lyndi N. Hewitt. 2001. "Volunteer Work and Well-being." Journal of Health and Social Behavior 42(2):115-131.

Umberson, Debra and Jennifer Karas Montez. 2010. "Social Relationships and Health: A Flashpoint for Health Policy." Journal of Health and Social Behavior 51(1_suppl):S54 -S66.

Vega, William A., Bohdan Kolody, Sergio Aguilar-Gaxiola, and Ralph Catalano. 1999. "Gaps in Service Utilization by Mexican Americans with Mental Health Problems.” The American Journal of Psychiatry 156:928-934.

Vaughan, Adam D., Monica Ly, Martin A. Andresen, Kathryn Wuschke, Tarah Hodgkinson, and Allison Campbell. 2018. "Concentrations and Specialization of Mental Health-related Calls for Police Service." Victims \& Offenders 13(8):1153-1170.

Watson, Amy C. 2010. "Research in the Real World: Studying Chicago Police Department's Crisis Intervention Team (CIT) Program." Research on Social Work Practice 20:536 -543 .

Watson, Amy C. and Jennifer D. Wood. 2017. "Everyday Police Work During Mental Health Encounters: A Study of Call Resolutions in Chicago and their Implications for Diversion." Behavioral Sciences \& the Law 35:442-455.

Weisburd, David, Breanne Cave, Matthew Nelson, Clair White, Amelia Haviland, Justin Ready, Brian Lawton, and Kathleen Sikkema. 2018. "Mean Streets and Mental Health: Depression and Post-Traumatic Stress Disorder at Crime Hot Spots." American Journal of Community Psychology 61(3-4):285-95. 
Wells, Kenneth, Ruth Klap, Alan Koike, and Cathy Sherbourne. 2001. "Ethnic Disparities in Unmet Need for Alcoholism, Drug Abuse, and Mental Health Care.” American Journal of Psychiatry 158(12):2027-2032.

White, Mary Castle, Linda Chafetz, Gerri Collins-Bride, and John Nickens. 2006. "History of Arrest, Incarceration and Victimization in Community-based Severely Mentally Ill." Journal of Community Health 31(2):123-135.

Williams, David R., Manuela Costa, and Jacinta P. Leavell. 2017. "Race and Mental Health." Pp. 281-303 in A Handbook for the Study of Mental Health: Social Contexts, Theories, and Systems (3rd edition), edited by T. L. Scheid and E. R. Wright. Cambridge, UK: Cambridge University Press.

Wilson, William J. 1987. The Truly Disadvantaged: The Inner City, the Underclass, and Public Policy. Chicago, IL: University of Chicago Press.

Wolch, Jennifer and Michael Dear. 1993. Malign Neglect: Homelessness in an American City. San Francisco, CA: Jossey-Bass. 


\section{Table 1.0. Descriptive Statistics by City $(N=606)$}

\begin{tabular}{|c|c|c|c|c|c|c|c|c|c|c|}
\hline & \multicolumn{3}{|c|}{ Baltimore $(n=193)$} & \multicolumn{3}{|c|}{ Detroit $(n=286)$} & \multicolumn{3}{|c|}{ Seattle $(n=127)$} & \multirow{2}{*}{$\begin{array}{c}\text { Chi-squared } \\
\text { Significance Leve } \\
\text { Test of Means }\end{array}$} \\
\hline & Mean & $S D$ & Range & Mean & SD & Range & Mean & $S D$ & Range & \\
\hline Population (100s) & 30.91 & 13.62 & $7.43-69.82$ & 23.78 & 10.86 & $4.36-58.06$ & 49.39 & 16.04 & $10.55-83.95$ & $* *$ \\
\hline Mental Health-related Calls & 15.40 & 10.45 & $0-58.00$ & 23.30 & 14.03 & $2.00-112.00$ & 34.86 & 43.01 & $0-287$ & $*$ \\
\hline Non-Mental Health-related Calls (100s) & 15.26 & 8.00 & $3.11-37.25$ & 7.86 & 3.47 & $1.41-18.05$ & 14.78 & 14.33 & $.12-81.59$ & NS \\
\hline Percent of Calls Mental Health-related & 1.01 & .52 & $0-2.77$ & 2.96 & 1.44 & $.62-11.74$ & 2.08 & 1.03 & $0-5.88$ & NS \\
\hline Mental Health Not Good (\%) & 14.52 & 3.63 & $6.40-25.30$ & 17.56 & 2.72 & $8.10-25.30$ & 9.59 & 1.92 & $6.80-15.50$ & NS \\
\hline Median Age & 35.67 & 6.32 & $20.50-63.80$ & 36.30 & 6.91 & $21.40-59.00$ & 37.15 & 5.24 & $21.40-51.80$ & NS \\
\hline Male (\%) & 46.85 & 4.58 & $33.10-59.60$ & 47.47 & 4.91 & $35.30-61.60$ & 50.19 & 3.94 & $43.20-64.30$ & NS \\
\hline Asian $(\%)$ & 2.16 & 3.11 & $0-18.50$ & .89 & 4.68 & $0-64.80$ & 14.06 & 12.13 & $2.40-63.50$ & $* * *$ \\
\hline Black $(\%)$ & 64.16 & 33.98 & $.90-100.00$ & 82.16 & 24.73 & $.80-100.00$ & 7.26 & 8.98 & $0-43.60$ & $* * *$ \\
\hline Hispanic (\%) & 4.43 & 6.20 & $0-390.00$ & 6.45 & 17.50 & $0-87.10$ & 6.40 & 5.17 & $1.10-41.10$ & NS \\
\hline Median Income (1000s) & 44.77 & 24.30 & $9.86-187.13$ & 26.20 & 11.07 & $9.46-111.88$ & 75.65 & 27.77 & $12.27-157.29$ & $* * *$ \\
\hline Not Graduated High School (\%) & 18.47 & 9.82 & $.70-47.90$ & 22.42 & 11.00 & $.60-69.50$ & 6.91 & 8.19 & $0-37.70$ & $*$ \\
\hline No Health Insurance (\%) & 10.53 & 4.92 & $1.00-35.10$ & 17.11 & 5.93 & $2.50-44.00$ & 8.81 & 4.83 & $.9-22.50$ & NS \\
\hline Veteran $(\%)$ & 6.68 & 2.51 & $.90-13.70$ & 6.37 & 2.96 & $0-18.20$ & 5.83 & 2.08 & $2.10-12.40$ & NS \\
\hline
\end{tabular}

Note.

$\mathrm{NS}=$ not statistically significant. ${ }^{*} p<.05 . * * p<.01 .{ }^{* * *} p<.001$. 
Table 1.1. Descriptive Statistics for all Three Cities Combined ( $N=606$ Census Tracts)

\begin{tabular}{lcccc}
\hline & Mean & SD & Min & Max \\
\hline Population (100s) & 31.41 & 16.23 & 4.36 & 83.95 \\
Mental Health-related Calls & 23.21 & 23.68 & 0 & 287 \\
Non-Mental Health-related Calls (100s) & 11.67 & 9.04 & .12 & 81.59 \\
Percent of Calls Mental Health-related & 2.15 & 1.42 & 0 & 11.74 \\
Mental Health Not Good (\%) & 14.92 & 4.21 & 6.4 & 25.3 \\
Median Age & 36.28 & 6.41 & 20.5 & 63.8 \\
Male (\%) & 47.84 & 4.77 & 33.1 & 64.3 \\
Asian (\%) & 4.05 & 8.42 & 0 & 64.8 \\
Black (\%) & 60.73 & 38.63 & 0 & 100 \\
Hispanic (\%) & 5.79 & 12.77 & 0 & 87.1 \\
Median Income (1000s) & 42.47 & 27.63 & 9.46 & 187.13 \\
Not Graduated High School (\%) & 17.91 & 11.69 & 0 & 69.5 \\
No Health Insurance (\%) & 13.27 & 6.53 & .9 & 44 \\
Veteran (\%) & 6.35 & 2.67 & 0 & 18.2 \\
\hline
\end{tabular}




\section{$\underline{\text { Table 1.2 Variable Correlations for Three Cities Combined ( } N=606 \text { Census Tracts) }}$}

\begin{tabular}{|c|c|c|c|c|c|c|c|c|c|c|c|c|c|}
\hline & $\begin{array}{l}\text { Mental } \\
\text { Health- } \\
\text { related } \\
\text { Calls }\end{array}$ & $\begin{array}{c}\text { Non } \\
\text { Mental } \\
\text { Health- } \\
\text { related } \\
\text { Calls } \\
\end{array}$ & $\begin{array}{l}\text { Median } \\
\text { Age }\end{array}$ & Male & Asian & Black & Hispanic & Veteran & $\begin{array}{c}\text { Mental } \\
\text { Health Not } \\
\text { Good }\end{array}$ & $\begin{array}{l}\text { Median } \\
\text { Income }\end{array}$ & $\begin{array}{c}\text { Not } \\
\text { Graduated } \\
\text { High School }\end{array}$ & $\begin{array}{l}\text { No Health } \\
\text { Insurance }\end{array}$ & Renter \\
\hline $\begin{array}{l}\text { Mental Health- } \\
\text { related Calls (\%) }\end{array}$ & 1.000 & & & & & & & & & & & & \\
\hline $\begin{array}{l}\text { Non Mental } \\
\text { Health-related } \\
\text { Calls }\end{array}$ & -.200 & 1.000 & & & & & & & & & & & \\
\hline Median Age & .100 & -.088 & 1.000 & & & & & & & & & & \\
\hline Male (\%) & .009 & .141 & .026 & 1.000 & & & & & & & & & \\
\hline Asian (\%) & -.063 & .199 & -.025 & .217 & 1.000 & & & & & & & & \\
\hline Black (\%) & .195 & -.129 & .090 & -.354 & -.515 & 1.000 & & & & & & & \\
\hline Hispanic (\%) & -.005 & -.006 & -.279 & .163 & .021 & -.411 & 1.000 & & & & & & \\
\hline Veteran (\%) & .062 & .021 & .416 & .025 & -.161 & .232 & -.271 & 1.000 & & & & & \\
\hline $\begin{array}{l}\text { Mental Health } \\
\text { Not Good }(\%)\end{array}$ & .255 & -.102 & -.259 & -.172 & -.387 & .672 & .108 & -.059 & 1.000 & & & & \\
\hline $\begin{array}{l}\text { Median Income } \\
(1000 s)\end{array}$ & -.277 & -.008 & .142 & .177 & .281 & -.685 & -.040 & -.038 & -.844 & 1.000 & & & \\
\hline $\begin{array}{l}\text { Not Graduated } \\
\text { High School }(\%)\end{array}$ & .150 & -.040 & -.169 & -.050 & -.154 & .338 & .447 & -.133 & .784 & -.651 & 1.000 & & \\
\hline $\begin{array}{l}\text { No Health } \\
\text { Insurance }(\%)\end{array}$ & .265 & -.103 & -.177 & .126 & -.093 & .295 & .360 & -.180 & .628 & -.587 & .613 & 1.000 & \\
\hline Renter (\%) & .114 & .294 & -.245 & .060 & .058 & .072 & .046 & -.113 & .288 & -.450 & .213 & .146 & 1.000 \\
\hline
\end{tabular}


Table 1.3. Model 1: Negative Binomial Estimates of Rates of Mental Health-related 911 Calls ( $N=606$ Census Tracts)

\begin{tabular}{|c|c|c|c|c|}
\hline Categories & Independent Variables & $\begin{array}{l}\text { Incidence } \\
\text { Rate Ratio } \\
\end{array}$ & $\begin{array}{c}\text { Standard } \\
\text { Error }\end{array}$ & $95 \% C I$ \\
\hline \multirow[t]{12}{*}{$\begin{array}{l}\text { Control Independent } \\
\text { Variables }\end{array}$} & Population (100s, logged as exposure) & 1 (constant) & - & - \\
\hline & City & & & \\
\hline & Detroit & $2.119 * * *$ & .153 & $1.839-2.442$ \\
\hline & Seattle & $1.889 * * *$ & .195 & $1.543-2.314$ \\
\hline & Median Age & $1.011 *$ & .005 & $1.002-1.020$ \\
\hline & Male (\%) & $1.011 *$ & .005 & $1.001-1.022$ \\
\hline & Asian $(\%)$ & $.991 *$ & .004 & $.983-.999$ \\
\hline & Black $(\%)$ & 1.001 & .002 & $.998-1.004$ \\
\hline & Hispanic $(\%)$ & $.992 *$ & .003 & $.986-.998$ \\
\hline & Veteran $(\%)$ & 1.009 & .010 & $.989-1.028$ \\
\hline & Mental Health Not Good (\%) & 1.019 & .017 & $.986-1.052$ \\
\hline & Non-Mental Health-Related Calls (100s) & $1.031 * * *$ & .003 & $1.026-1.038$ \\
\hline \multirow[t]{4}{*}{$\begin{array}{l}\text { Focal Independent } \\
\text { Variables }\end{array}$} & Median Income (1000s) & $.992 * * *$ & .002 & $.987-.996$ \\
\hline & Not Graduated High School (\%) & 1.003 & .005 & $.994-1.012$ \\
\hline & No Health Insurance (\%) & 1.001 & .006 & $.990-1.012$ \\
\hline & Renter $(\%)$ & $1.009 * * *$ & .002 & $1.006-1.012$ \\
\hline
\end{tabular}

Note

$* p<.05 . * * p<.01 . * * * p<.001$.

Dispersion (alpha): .239. Pseudo $\mathrm{R}^{2}$ : .0983. 
Table 1.4. Models 2-4: Negative Binomial Regression Results of Rates of Mental Health-related 911 Calls $\underline{(N=606}$ Census Tracts)

\begin{tabular}{|c|c|c|c|c|c|c|c|c|c|}
\hline & & Model 2 & & & Model 3 & & & Model 4 & \\
\hline Independent Variables & $\begin{array}{l}\text { Incidence } \\
\text { Rate Ratio }\end{array}$ & $\begin{array}{l}\text { Standard } \\
\text { Error }\end{array}$ & $95 \% C I$ & $\begin{array}{l}\text { Incidence } \\
\text { Rate Ratio }\end{array}$ & $\begin{array}{l}\text { Standard } \\
\text { Error }\end{array}$ & $95 \% C I$ & $\begin{array}{l}\text { Incidence } \\
\text { Rate Ratio }\end{array}$ & $\begin{array}{l}\text { Standard } \\
\text { Error }\end{array}$ & $95 \% C I$ \\
\hline $\begin{array}{l}\text { Population } \\
\text { (100s, logged as exposure) }\end{array}$ & 1 (constant) & - & - & 1 (constant) & - & - & 1 (constant) & - & - \\
\hline City & & . & & & & & & & \\
\hline Detroit & $2.074 * * *$ & .138 & $1.821-2.362$ & $2.323 * * *$ & .157 & $2.034-2.652$ & $2.095 * * *$ & .138 & $1.841-2.384$ \\
\hline Seattle & $1.796 * * *$ & .148 & $1.528-2.111$ & $1.600 * * *$ & .133 & $1.359-1.884$ & $1.751 * * *$ & .140 & $1.497-2.048$ \\
\hline $\begin{array}{l}\text { Non-Mental Health-Related } \\
\text { Calls (100s) }\end{array}$ & $1.035 * * *$ & .003 & $1.029-1.041$ & $1.041 * * *$ & .003 & $1.035-1.048$ & $1.034 * * *$ & .003 & $1.028-1.040$ \\
\hline Mental Health Not Good (\%) & 1.014 & .112 & $.991-1.036$ & $1.076 * * *$ & .009 & $1.058-1.095$ & - & - & - \\
\hline Median Income (1000s) & $.986 * * *$ & .002 & $.983-.987$ & - & - & - & $.985 * * *$ & .001 & $.982-.987$ \\
\hline
\end{tabular}

Note

$* p<.05 . * * p<.01 . * * * p<.001$.

Model 3 Pseudo R ${ }^{2}$ : 0838.

Model 4 Pseudo $\mathrm{R}^{2}$ : .0723.

Model 5 Pseudo $\mathrm{R}^{2}$ : 0835 . 


\title{
Appendix I: Call Codes Categorized as Being Mental Health-related
}

This appendix contains the exact wording (including original typological errors) of the call codes that I categorized as being mental health-related by city.

\author{
Baltimore \\ "MENTAL CASE" \\ NEEDS E/P" \\ "NEEDS TO BE E/P" \\ "NEEDS TO E/P" \\ "P/U EMGNCY PETIT" \\ "PHYCH WALK OUT" \\ "PICK E/P PAPER" \\ "PICKUP E/P ORDER" \\ "PICKUP E/P PAPER" \\ "REF TO EMER.PET." \\ "ATT SUICIDE" \\ "SUICIDAL" \\ "THREATING SUICIDE" \\ "INOLV DETENTION" \\ "ESCAPEE PSYCH PATIENT" \\ "CHANGE IN MENTAL" \\ "ESCAPEE PSYCH PT" \\ "HIGH RISK PATIEN" I \\ "mental case" \\ "PHYCH WALK OUT" \\ "PICIKUP E/P PAPE" \\ "PICK E/P PAPER" \\ "PICK UP EP" \\ "PICK UP EP PPRS" \\ "POSS MENTAL" \\ "POSS MENTAL CASE" \\ "THREATING SUICID" \\ "VIOLENT OVERDOSE" \\ "VOLUNTARY DENT" \\ "EMEG PETITION" \\ "EMEG. PETITION" \\ "EMEMG. PETITION" \\ "EMER PETITION" \\ "EMER PET" \\ "EMER PETITIO" \\ "EMER PETITION" \\ "EMER PETITITON" \\ "EMER PETITON" \\ "EMER PETTION"
}


"EMER. EVAL"

"EMER. PET."

"EMER. PETITION"

"EMERCY PETITION"

"EMERENCY PETITIO"

"EMERG PET"

"EMERG PETITION"

"EMERG PRT"

"EMERG P"

"EMERG PETET"

"EMERG PETETION"

"EMERG PETIITION"

"EMERG PETIT"

"EMERG PETITION"

"EMERG PETITITON"

"EMERG PETITON"

"EMERG PETTION"

"EMERG. EVAL."

"EMERG. EVALUAT."

"EMERG. PEITITION"

"EMERG. PET."

"EMERG. PETIT."

"EMERG. PETITION"

"EMERGE PETITION"

"EMERGE PETTION"

"EMERGECY PETITIO"

"EMERGENCT PETIT"

"EMERGENCU PETIT"

"EMERGENCY PETIT"

"EMERGENCY EVAL"

"EMERGENCY PARTIT"

"EMERGENCY PET"

"EMERGENCY PET."

"EMERGENCY PETEIT"

"EMERGENCY PETETI"

"EMERGENCY PETIO"

"EMERGENCY PETION"

"EMERGENCY PETIT"

"EMERGENCY PETIT."

"EMERGENCY PETITI"

"EMERGENCY PETITO"

"EMERGENCY PETTIO"

"EMERGENCY PETTIT"

"EMERGENCY [ETITI"

"EMERGMENTAL CASE"

"EMERGNCY PETIT" 
"EMG PETITION"

"EMNGY PETITION"

"EMRG PETIT"

"EMRGENCY PETITIO"

"EMRGNCY PETITON"

"ENERGENCY PET"

"EP"

"EP PAPERS"

"EP ASSISTANCE"

"EP FOR 85"

"EP PAPAERS"

"EP PAPER"

"EP PAPER PICKUP"

"EP PAPERS"

"EP PAPERWORK"

"EP PAPRES"

"EP PETION"

"EP PETTION"

"EP PICK UP"

"EP REQUEST"

"EP pAPERS"

"EP/PAPERS"

"ER PETITION"

"ERMEG. PETITION"

\section{Detroit}

"ATTEMPTED SUICIDE REPORT"

"MENTAL"

"MENTAL NOT VIOLENT"

"MENTAL VIOLENT - ARMED"

"MENTAL VIOLENT NOT ARMED"

"MNTL PPRS/CRISIS"

"MNTL-VIO ARMD"

"MNTL-VIO NT ARM"

"SUICIDE ATTEMPT DELTA"

"SUICIDE I/P"

"SUICIDE REPT"

"SUICIDE THREAT"

"SUICIDE THREAT OR ABNORM BEHAV"

\section{Seattle}

"CRISIS COMPLAINT - GENERAL"

"CRISIS COMPLAINT - PICK-UP OR TRANSPORT"

"MENTAL COMPLAINT"

"MENTAL PERSON PICK-UP OR TRANSPORT" 


\section{Appendix II: Separate City Analyses of Correlations Between Call Types}

\section{$\underline{\text { Table 1.5 Baltimore Correlations Call Types ( } N=193 \text { Census Tracts) }}$}

\begin{tabular}{|c|c|c|c|c|c|c|c|}
\hline & $\begin{array}{l}\text { Total } 911 \\
\quad \text { Calls }\end{array}$ & $\begin{array}{l}\text { Total } 911 \text { Calls } \\
\text { per Capita }\end{array}$ & $\begin{array}{l}\text { Mental Health- } \\
\text { related Calls }\end{array}$ & $\begin{array}{c}\text { Percent Mental } \\
\text { Health-related } \\
\text { Calls }\end{array}$ & $\begin{array}{l}\text { Mental Health- } \\
\text { related Calls per } \\
\text { Capita }\end{array}$ & $\begin{array}{l}\text { Non Mental Health- } \\
\text { related Calls }\end{array}$ & $\begin{array}{c}\text { Non Mental Health- } \\
\text { related Calls per } \\
\text { Capita } \\
\end{array}$ \\
\hline Total 911 Calls & 1.000 & & & & & & \\
\hline Total 911 Calls per Capita & .600 & 1.000 & & & & & \\
\hline Mental Health-related Calls & 687 & .381 & 1.000 & & & & \\
\hline $\begin{array}{l}\text { Percent Mental Health-related } \\
\text { Calls }\end{array}$ & -.038 & -.009 & .614 & 1.000 & & & \\
\hline $\begin{array}{l}\text { Mental Health-related Calls per } \\
\text { Capita }\end{array}$ & .318 & .692 & .654 & .606 & 1.000 & & \\
\hline Non Mental Health-related Calls & 1.000 & .601 & .680 & -.046 & .313 & 1.000 & \\
\hline $\begin{array}{l}\text { Non Mental Health-related Calls } \\
\text { per Capita }\end{array}$ & .602 & 1.000 & .376 & -.019 & .684 & .602 & 1.000 \\
\hline
\end{tabular}


Table 1.6 Detroit Correlations Call Types $(N=286$ Census Tracts)

\begin{tabular}{|c|c|c|c|c|c|c|c|}
\hline & $\begin{array}{l}\text { Total } 911 \\
\text { Calls }\end{array}$ & $\begin{array}{l}\text { Total } 911 \text { Calls } \\
\text { per Capita }\end{array}$ & $\begin{array}{l}\text { Mental Health- } \\
\text { related Calls }\end{array}$ & $\begin{array}{c}\text { Percent Mental } \\
\text { Health-related } \\
\text { Calls } \\
\end{array}$ & $\begin{array}{l}\text { Mental Health- } \\
\text { related Calls per } \\
\text { Capita }\end{array}$ & $\begin{array}{l}\text { Non Mental Health- } \\
\text { related Calls }\end{array}$ & $\begin{array}{l}\text { Non Mental Health- } \\
\text { related Calls per } \\
\text { Capita }\end{array}$ \\
\hline Total 911 Calls & 1.0000 & & & & & & \\
\hline Total 911 Calls per Capita & .284 & 1.000 & & & & & \\
\hline Mental Health-related Calls & .668 & .289 & 1.000 & & & & \\
\hline $\begin{array}{l}\text { Percent Mental Health-related } \\
\text { Calls }\end{array}$ & -.124 & .040 & .560 & 1.000 & & & \\
\hline $\begin{array}{l}\text { Mental Health-related Calls per } \\
\text { Capita }\end{array}$ & .120 & .682 & .628 & .698 & 1.000 & & \\
\hline Non Mental Health-related Calls & 1.000 & .280 & .646 & -.150 & .097 & 1.0000 & \\
\hline $\begin{array}{l}\text { Non Mental Health-related Calls } \\
\text { per Capita }\end{array}$ & .288 & .999 & .267 & .006 & .654 & .285 & 1.0000 \\
\hline
\end{tabular}




\section{Table 1.7 Seattle Correlations Call Types ( $N=127$ Census Tracts)}

\begin{tabular}{|c|c|c|c|c|c|c|c|}
\hline & $\begin{array}{l}\text { Total } 911 \\
\text { Calls }\end{array}$ & $\begin{array}{l}\text { Total } 911 \text { Calls } \\
\text { per Capita }\end{array}$ & $\begin{array}{l}\text { Mental Health- } \\
\text { related Calls }\end{array}$ & $\begin{array}{c}\text { Percent Mental } \\
\text { Health-related } \\
\text { Calls } \\
\end{array}$ & $\begin{array}{l}\text { Mental Health- } \\
\text { related Calls per } \\
\text { Capita }\end{array}$ & $\begin{array}{l}\text { Non Mental Health- } \\
\text { related Calls }\end{array}$ & $\begin{array}{l}\text { Non Mental Health- } \\
\text { related Calls per } \\
\text { Capita }\end{array}$ \\
\hline Total 911 Calls & 1.000 & & & & & & \\
\hline Total 911 Calls per Capita & .817 & 1.000 & & & & & \\
\hline Mental Health-related Calls & .904 & .716 & 1.000 & & & & \\
\hline $\begin{array}{l}\text { Percent Mental Health-related } \\
\text { Calls }\end{array}$ & .221 & .168 & .497 & 1.000 & & & \\
\hline $\begin{array}{l}\text { Mental Health-related Calls per } \\
\text { Capita }\end{array}$ & .803 & .939 & .847 & .413 & 1.000 & & \\
\hline Non Mental Health-related Calls & 1.000 & .817 & .898 & .212 & .800 & 1.000 & \\
\hline $\begin{array}{l}\text { Non Mental Health-related Calls } \\
\text { per Capita }\end{array}$ & .816 & 1.000 & .711 & .161 & .936 & .817 & 1.000 \\
\hline
\end{tabular}




\section{Appendix III: Separate City Analyses of Key Independent Variables}

Table 1.8. Baltimore Negative Binomial Regression Results of Rates of Mental Health-related 911 Calls $\underline{(N=193 \text { Census Tracts) }}$

\begin{tabular}{|c|c|c|c|c|c|c|c|c|c|}
\hline & & Model 1 & & & Model 2 & & & Model 3 & \\
\hline Independent Variables & $\begin{array}{l}\text { Incidence } \\
\text { Rate Ratio }\end{array}$ & $\begin{array}{l}\text { Standard } \\
\text { Error }\end{array}$ & $95 \% C I$ & $\begin{array}{l}\text { Incidence } \\
\text { Rate Ratio }\end{array}$ & $\begin{array}{l}\text { Standard } \\
\text { Error }\end{array}$ & $95 \% C I$ & $\begin{array}{l}\text { Incidence } \\
\text { Rate Ratio }\end{array}$ & $\begin{array}{l}\text { Standard } \\
\text { Error }\end{array}$ & $95 \% C I$ \\
\hline $\begin{array}{l}\text { Population } \\
\text { (100s, logged as exposure) }\end{array}$ & 1 (constant) & - & - & 1 (constant) & - & - & 1 (constant) & - & - \\
\hline $\begin{array}{l}\text { Non-Mental Health-Related } \\
\text { Calls (100s) }\end{array}$ & $1.022 * * *$ & .006 & $1.011-1.033$ & $1.024 * * *$ & .006 & $1.013-1.036$ & $1.023 * * *$ & .006 & $1.012-1.034$ \\
\hline Mental Health Not Good (\%) & 1.035 & .006 & $.996-1.075$ & $1.106^{* * *}$ & .014 & $1.078-1.135$ & - & - & - \\
\hline Median Income (1000s) & $.986 * * *$ & .003 & $.980-.992$ & - & - & - & $.982 * * *$ & .002 & $.978-.986$ \\
\hline
\end{tabular}

$$
\text { Note }
$$

$* p<.05 . * * p<.01 . * * * p<.001$.

Model 1 Pseudo $\mathrm{R}^{2}: .0726$.

Model 2 Pseudo $R^{2}: .0594$.

Model 3 Pseudo $R^{2}$ : .0705. 
Table 1.9. Detroit Negative Binomial Regression Results of Rates of Mental Health-related 911 Calls ( $N=286$ Census Tracts)

\begin{tabular}{|c|c|c|c|c|c|c|c|c|c|}
\hline & & Model 1 & & & Model 2 & & & Model 3 & \\
\hline Independent Variables & $\begin{array}{l}\text { Incidence } \\
\text { Rate Ratio }\end{array}$ & $\begin{array}{l}\text { Standard } \\
\text { Error }\end{array}$ & $95 \% C I$ & $\begin{array}{l}\text { Incidence } \\
\text { Rate Ratio }\end{array}$ & $\begin{array}{l}\text { Standard } \\
\text { Error }\end{array}$ & $95 \% C I$ & $\begin{array}{l}\text { Incidence } \\
\text { Rate Ratio }\end{array}$ & $\begin{array}{l}\text { Standard } \\
\text { Error }\end{array}$ & $95 \% C I$ \\
\hline $\begin{array}{l}\text { Population } \\
\text { (100s, logged as exposure) }\end{array}$ & 1 (constant) & - & - & 1 (constant) & - & - & 1 (constant) & - & - \\
\hline $\begin{array}{l}\text { Non-Mental Health-Related } \\
\text { Calls (100s) }\end{array}$ & $1.022 *$ & .010 & $1.003-1.041$ & $1.024 *$ & .010 & $1.004-1.043$ & $1.022^{*}$ & .010 & $1.003-1.041$ \\
\hline Mental Health Not Good (\%) & 1.000 & .018 & $.966-1.035$ & $1.051 * * *$ & .013 & $1.026-1.077$ & - & - & - \\
\hline Median Income (1000s) & $.983 * * *$ & .004 & $.975-.992$ & - & - & - & $.983 * * *$ & .003 & $.978-.989$ \\
\hline
\end{tabular}

Note

$* p<.05 . * * p<.01 . * * * p<.001$.

Model 1 Pseudo $\mathrm{R}^{2}: .0156$.

Model 2 Pseudo $\mathrm{R}^{2}: .0092$.

Model 3 Pseudo R²: 0156. 
Table 1.10. Seattle Negative Binomial Regression Results of Rates of Mental Health-related 911 Calls ( $N=127$ Census Tracts)

\begin{tabular}{|c|c|c|c|c|c|c|c|c|c|}
\hline \multirow[b]{2}{*}{ Independent Variables } & \multicolumn{3}{|c|}{ Model 1} & \multicolumn{3}{|c|}{ Model 2} & \multicolumn{3}{|c|}{ Model 3} \\
\hline & $\begin{array}{l}\text { Incidence } \\
\text { Rate Ratio }\end{array}$ & $\begin{array}{l}\text { Standard } \\
\text { Error }\end{array}$ & $95 \% C I$ & $\begin{array}{l}\text { Incidence } \\
\text { Rate Ratio }\end{array}$ & $\begin{array}{l}\text { Standard } \\
\text { Error }\end{array}$ & $95 \% C I$ & $\begin{array}{l}\text { Incidence } \\
\text { Rate Ratio }\end{array}$ & $\begin{array}{l}\text { Standard } \\
\text { Error }\end{array}$ & $95 \% C I$ \\
\hline $\begin{array}{l}\text { Population } \\
\text { (100s, logged as exposure) }\end{array}$ & 1 (constant) & - & - & 1 (constant) & - & - & 1 (constant) & - & - \\
\hline $\begin{array}{l}\text { Non-Mental Health-Related } \\
\text { Calls (100s) }\end{array}$ & $1.043 * * *$ & .005 & $1.034-1.052$ & $1.051 * * *$ & .005 & $1.041-1.062$ & $1.044 * * *$ & .005 & $1.034-1.053$ \\
\hline Mental Health Not Good (\%) & .959 & .039 & $.885-1.040$ & $1.089 * *$ & .035 & $1.022-1.161$ & - & - & - \\
\hline Median Income (1000s) & $.987 * * *$ & .003 & $.981-.993$ & - & - & - & $.989 * * *$ & .001 & $.004-.010$ \\
\hline
\end{tabular}

Note

$* p<.05 . * * p<.01 . * * * p<.001$.

Model 1 Pseudo $\mathrm{R}^{2}: .1240$.

Model 2 Pseudo $\mathrm{R}^{2}: .1090$.

Model 3 Pseudo $\mathrm{R}^{2}: .1231$. 